\title{
A comparison of mitochondrial and nuclear DNA status in testicular sperm from fertile men and those with obstructive azoospermia
}

\author{
M.O'Connell ${ }^{1}$, N.McClure ${ }^{1,2}$ and S.E.M.Lewis ${ }^{1,3}$ \\ ${ }^{1}$ School of Medicine, Department of Obstetrics and Gynaecology, Queens' University Belfast, Institute of Clinical Science, \\ Grosvenor Road, Belfast BT12 6BJ, and ${ }^{2}$ Regional Fertility Centre, Royal Maternity Hospital, Belfast BT12 6BJ, UK \\ ${ }^{3}$ To whom correspondence should be addressed. E-mail: s.e.lewis@qub.ac.uk
}

BACKGROUND: Mitochondria are vital to sperm as their motility powerhouses. They are also the only animal organelles with their own unique genome; encoding subunits for the complexes required for the electron transfer chain. METHODS: A modified long PCR technique was used to study mitochondrial DNA (mtDNA) in ejaculated and testicular sperm samples from fertile men undergoing vasectomy $(\mathrm{n}=11)$ and testicular sperm from men with obstructive azoospermia $(n=25)$. Nuclear DNA (nDNA) fragmentation was measured by an alkaline gel electrophoresis (comet) assay. RESULTS: Wild-type mtDNA was detected in only $60 \%$ of fertile men's testicular sperm, $50 \%$ of their ejaculated sperm and $46 \%$ of testicular sperm from men with obstructive azoospermia. The incidence of mitochondrial deletions in testicular sperm of fertile and infertile men was not significantly different, but the mean size of the deletions was significantly less in testicular sperm from fertile men compared with men with obstructive azoospermia $(P<0.02)$. NDNA fragmentation in testicular sperm from fertile men and men with obstructive azoospermia was not significantly different. CONCLUSION: Multiple mtDNA deletions are common in testicular and ejaculated sperm from both fertile and infertile men. However, in males with obstructive azoospermia, the mtDNA deletions in testicular sperm are of a larger scale.

Key words: human sperm/male infertility/mitochondrial and nuclear DNA/obstructive azoospermia/ROS

\section{Introduction}

Sperm mitochondria are uniquely positioned in the midpiece in order to provide energy quickly and effectively for sperm motility. These mitochondria facilitate the sperm's rigorous demands for energy by means of oxidative phosphorylation (OXPHOS) via the electron transport chain (ETC). The ETC is made up of subunits that are synthesized by the mitochondrial DNA (mtDNA) except for complex II, which is encoded in the nucleus. It is the communication that exists within these complexes and ETC that produces ATP.

Mitochondria are also important to sperm in that they are the only organelles that contain their own genome: mtDNA. The mitochondrial genome consists only of exons with no introns between genes. Therefore, every point mutation, or deletion, has the capacity to affect the mitochondrial function of cellular respiration support. MtDNA also lacks the protection of histones or DNA binding proteins (Shoffner et al., 1993) and is believed to have only a very basic repair mechanism (Croteau et al., 1999). Bohr and Dianov have reported that this mechanism can repair excision and bases caused by oxidative insult (Bohr and Dianov, 1999). The mitochondrion also replicates rapidly, without a significant proofreading system and has a mutation rate 10-100 times higher than that of nuclear DNA (nDNA) (Pesole et al., 1999).
Mutations in mtDNA have been implicated as aetiological factors in a number of human genetic diseases (Wallace, 1993). Most of these mtDNA mutations are causally related to distinct neuromuscular and neurodegenerative diseases. Point mutations can lead, for example, to myoclonic epilepsy with ragged red fibres (MERRF) and to mitochondrial encephalomyopathy_lactic acidosis — strokelike episodes (MELAS). Largescale rearrangements are associated with Kearns-Sayre syndrome (KSS), progressive external ophthalmoplegia (PEO) and other multisystemic disorders (Lestienne, 1992), such as Alzheimer's and Parkinson's diseases (Wallace et al., 1994). Nuclear gene defects may also result in mitochondrial disorders by predisposing the cell to multiple mtDNA deletions, (Bourgeron, 2000). However, the full extent of the relationship between the status of mtDNA and nuclear DNA in either somatic cells or sperm has not yet been determined.

In sperm, specific mtDNA deletions have been associated with inadequate sperm function. For example, Kao et al. recently found that multiple deletions of 7345 and 7599 bp mtDNA were associated with poor sperm motility (Kao et al., 1995, 1998). Lestienne et al. also found that oligoasthenozoospermia was associated with multiple mtDNA rearrangements (Lestienne et al., 1997). Similarly, St John et al. found multiple deletions in testicular biopsies of azoospermic and severe 
oligozoospermic men (St John et al., 1997). Conversely, Cummins et al. found significant levels of mtDNA deletions in men with normal semen profiles, whose sperm was phenotypically normal (Cummins et al., 1998). Since there is now evidence of paternal mtDNA in normal and abnormal embryos created by IVF and ICSI (St John et al., 2000a) it is particularly important to characterize the status of this genome within sperm.

This is the first study, to our knowledge, that exemplifies the mtDNA mutations of testicular sperm from fertile and infertile men. Here we obtained testicular sperm from men with obstructive azoospermia and testicular and ejaculated sperm from subjects undergoing vasectomy. We used LPCR to determine the presence of mtDNA fragments within $8.7 \mathrm{~kb}$ of the $16.6 \mathrm{~kb}$ DNA molecule and a modified alkaline comet assay to assess nuclear DNA (nDNA) (Hughes et al., 1997; Donnelly et al., 1999).

\section{Materials and methods}

\section{Subjects}

Testicular biopsies were obtained from men with obstructive azoospermia $(n=25)$ attending the Regional Fertility Centre, Belfast as previously reported (Steele et al., 2000). Patients with obstructive azoospermia were classified as men with two azoospermic semen analyses, normal FSH and LH levels and a normal karyotype to exclude men with non-obstructive azoospermia.

Men, of recent proven fertility, who were having vasectomies under general anaesthesia were recruited as controls $(n=11)$ in the Day Procedure Unit, Royal Hospital's Trust, Belfast. They were asked to provide an ejaculated semen sample in the week prior to their operation. All samples had normozoospermic profiles with $<10^{6}$ leukocytes per ml (World Health Organization, 1999). Each man then had a testicular biopsy at the time of his vasectomy. Informed consent for participation was obtained and the project was approved by Queens' University Belfast, Research and Ethics Committee.

\section{Preparation of ejaculated sperm by Percoll density centrifugation}

After seminal liquefaction, a routine semen analysis was performed according to World Health Organization (1999) guidelines using light microscopy to determine concentration and motility. Morphology was assessed by the Tygerberg (strict) criteria (Kruger et al., 1986).

Ejaculated samples were prepared using a two-step discontinuous Percoll gradient (95.0 and 47.5\%; Pharmacia Biotech AB, Uppsala, Sweden). An aliquot of liquefied semen was layered on top of the gradient and centrifuged (450 $\mathrm{g}, 12 \mathrm{~min})$. The resulting sperm pellet was concentrated by centrifugation $(200 \mathrm{~g}$, $6 \mathrm{~min}$ ). The final sperm preparation was suspended in $250 \mu$ l Biggers-Whitten-Whittingham medium (BWW; Biggers et al., 1971) supplemented with $600 \mathrm{mg}$ albutein (Alpha Therapeutic UK Ltd, Norfolk, UK).

\section{Testicular biopsy and sperm preparation (Steele et al., 2000)}

Briefly the spermatic cord was located and $10 \mathrm{ml}$ of $0.5 \%$ bupivacaine injected around it. Five minutes later the testis was firmly palpated to ensure numbness. A 14 gauge Trucut biopsy needle (Baxter Healthcare Ltd, Thetford, Norfolk,UK) was passed into the testes and the biopsy transferred into BWW medium.

Testicular sperm were retrieved from the seminiferous tubules by 'milking' the tubular contents with size 5 jeweller's forceps into
BWW, under a dissecting microscope. The contents of the seminiferous tubule were then centrifuged $(110 \mathrm{~g}, 10 \mathrm{~min})$ to remove debris and the sperm pellet resuspended.

\section{Determination of mtDNA mutations by LPCR/sperm DNA isolation}

A million cells were added to a $15 \mathrm{ml}$ tube. This was centrifuged (2000 $\mathrm{g}, 3 \mathrm{~min}$ ) to pellet the cells and the supernatant removed, leaving behind $200-400 \mu \mathrm{l}$ residual liquid. The tube was vortexed vigorously to resuspend the cells in the residual supernatant: this facilitates cell lysis. To the resuspended cells $3.0 \mathrm{ml}$ of Cell Lysis Solution (Flowgen, Ashby de la Zouche, Staffordshire, UK) was added and pipetted up and down to mix. Dithiothreitol (DTT, $200 \mu \mathrm{l}$ ), (1M, Sigma, Poole, Dorset, UK) were added followed by $1.5 \mu \mathrm{l}$ Proteinase K (20 mg/ml, Sigma). This mix was inverted 25 times and incubated at $55^{\circ} \mathrm{C}$ overnight until the cells had completely lysed.

RNase A solution (Flowgen) $15 \mu \mathrm{l}$ was added to the cell lysate and the sample inverted 25 times to aid mixing before incubation at $37^{\circ} \mathrm{C}$ for $15-60 \mathrm{~min}$. The sample was cooled to room temperature $\sim 22^{\circ} \mathrm{C}$, and $100 \mu \mathrm{l}$ of protein precipitate solution was added to the RNase A-treated cell lysate; this was then vortexed to mix the sample. The sample was placed on ice for $5 \mathrm{~min}$ and then centrifuged $(2000 \mathrm{~g}$, $10 \mathrm{~min}$ ). The precipitated proteins formed a tight pellet; the supernatant that contained the DNA was poured into a $1.5 \mathrm{ml}$ Eppendorf tube containing $300 \mu \mathrm{l}$ isopropanol (100\%, Sigma). This was centrifuged ( $2000 \mathrm{~g}$, $3 \mathrm{~min}$ ) prior to mixing. The supernatant was poured off and the Eppendorf tube drained on clean absorbent paper. Ethanol, $2 \mathrm{ml}$ (70\%, Sigma) was added to the Eppendorf to wash the DNA pellet before being centrifuged ( $2000 \mathrm{~g}, 3 \mathrm{~min})$. The ethanol was poured off so as not to disturb the DNA. The Eppendorf tube was inverted and allowed to dry for $15 \mathrm{~min}$.

Four hundred microlitres of DNA hydration solution (Flowgen) were added to the DNA. This was heated at $65^{\circ} \mathrm{C}$ for $1 \mathrm{~h}$, to rehydrate.

\section{DNA calibration}

Deionized and distilled water (DDW) $(490 \mu \mathrm{l})$ were added to a $0.5 \mathrm{ml}$ quartz quvette (Sigma) and mixed with $10 \mu \mathrm{l}$ of the hydrated DNA sample. The DNA quantity was calculated at $260 \mathrm{~nm}$ using a Ultrospec II, LKB Biochrom spectrophotometer.

\section{LPCR amplification $(8.7 \mathrm{~kb})$}

LPCR products were amplified in a Hybaid, TouchDown thermal cycling system (Hybaid Ltd, Middlesex, UK). LPCR using Bio-XAct (Bioline, London, UK) was performed in $50 \mu \mathrm{l}$ volumes. Each reaction contained $1 \times$ Optiform PCR Buffer (Bioline) $0.25 \mathrm{~mol} / \mathrm{l}$ dNTPs, 500 ng DNA template, $1.5 \mathrm{mM} \mathrm{MgCl}_{2}, 2 \mathrm{U}$ of Bio-X-Act (Bioline) and $0.5 \mu \mathrm{M}$ of each primer (D6: 5'TCT AGA GCC CAG CAC TGT AAA G 3' L strand sequence, position 8286-8304 and R10: 5' AGT GCA TAC CGC CAA AAG AAG A 3'- L strand sequence position 421-403 (Lestienne et al., 1997). In brief, the steps consisted of initial denaturation at $94^{\circ} \mathrm{C}$ for $2 \mathrm{~min}$, followed by 34 cycles of denaturation at $94^{\circ} \mathrm{C}$ for $10 \mathrm{~s}$, annealing at $52^{\circ} \mathrm{C}$ for $30 \mathrm{~s}$ and extension at $68^{\circ} \mathrm{C}$ for $10 \mathrm{~min}$. The 'semi-hot' technique was employed:. the reaction tubes, with all the components present, were placed in the PCR machine at the start of the denaturation phase.

Of the mitochondrial genome $8.7 \mathrm{~kb}$ out of the $16.6 \mathrm{~kb}$ was amplified from whole sperm samples. This region was chosen as it encompasses the most heavily deleted region of the genome. The region amplified incorporated the following genes: complex I, the NADH dehydrogenase genes; complex III, cytochrome b; complex IV, the cytochrome C oxidase gene and CO III; and complex V, with the ATP synthase genes and up to nine of the tRNA genes (Lestienne et al., 1997). 
In each reaction, one negative control and one positive blood control sample were run to determine whether mispriming of the multienzyme system had taken place. LPCR was repeated in the same samples to ensure reproducibility of the proportions of deleted mtDNA molecules and identical mutations were found.

The reaction products were electrophoresed on a $0.8 \%$ agarose, TBA (Gibco, Invitrogen Ltd, Paisley, Scotland, UK) gel containing ethidium bromide $(1 \mu \mathrm{g} / \mathrm{ml})$ at $120 \mathrm{~V}$ for $60 \mathrm{~min}$.

Determination of DNA integrity by modified alkaline single cell gel electrophoresis (comet) assay

The following procedure was carried out under yellow light to prevent further induced DNA damage (Hughes et al., 1997; Donnelly et al., 1999, 2000).

\section{Embedding of sperm in agarose gel}

Fully frosted microscope slides (Richardsons Co Ltd, London, UK) were gently heated, covered with $100 \mu \mathrm{l}$ of $0.5 \%$ normal melting point agarose in $\mathrm{Ca}^{2+}$ and $\mathrm{Mg}^{2}$-free phosphate buffered saline (PBS; Sigma-Aldrich Company Ltd, Poole, Dorset, UK) $<45^{\circ} \mathrm{C}$ and immediately covered with a large $(22 \times 50 \mathrm{~mm})$ coverslip. The slides were placed in a chilled metal tray and left at $4{ }^{\circ} \mathrm{C}$ for at least $30 \mathrm{~min}$ to allow the agarose to solidify. The coverslips were then removed and $1 \times 10^{5}$ sperm in $10 \mu \mathrm{lBWW}$ were mixed with $75 \mu \mathrm{l}$ of $0.5 \%$ low melting point agarose at $37^{\circ} \mathrm{C}$. This cell suspension was rapidly pipetted on top of the first agarose layer, covered with a coverslip and allowed to solidify at room temperature.

\section{Lysing of cells and decondensation of DNA}

The coverslips were removed and the slides immersed in a Coplin jar containing freshly prepared cold lysing solution $(2.5 \mathrm{~mol} / \mathrm{l} \mathrm{NaCl}$; $100 \mathrm{~mol} / \mathrm{l} \mathrm{Na} 2$ EDTA; 10 mol/l Tris; $\mathrm{pH}$ : 10, with $1 \%$ Triton X-100 (Sigma-Aldrich Company) added just before use for $1 \mathrm{~h}$ at $4^{\circ} \mathrm{C}$. Subsequently, slides were incubated for $30 \mathrm{~min}$ at $4^{\circ} \mathrm{C}$ with $10 \mathrm{~mol} / \mathrm{l}$ (DTT) dithiothreitol followed by a $90 \mathrm{~min}$ incubation at $20^{\circ} \mathrm{C}$ with $4 \mathrm{~mol} / \mathrm{l}$ lithium diiodosalicyclate (LIS; Sigma-Aldrich) (Robbins et al., 1993).

\section{Unwinding of DNA}

Slides were removed from the lysis solution, DTT + LIS and carefully drained of any remaining liquid. A horizontal gel electrophoresis tank was filled with fresh alkaline electrophoresis solution $(300 \mathrm{~mol} / \mathrm{l}$ $\mathrm{NaOH}$; 1 mol/l EDTA; pH: 13.0; (Sigma-Aldrich) at $12-15^{\circ} \mathrm{C}$. The slides were placed into this tank side by side, with the agarose end facing the anode, and covered with electrophoresis buffer to a level of approximately $0.25 \mathrm{~cm}$ above the slide surface. The slides were left in this high $\mathrm{pH}$ buffer for 20 min to allow DNA in the cells to unwind.

\section{Separation of DNA fragments by electrophoresis}

Electrophoresis was conducted for $10 \mathrm{~min}$ at $25 \mathrm{~V}(0.714 \mathrm{~V} / \mathrm{cm})$ adjusted to $300 \mathrm{~mA}$ by raising or lowering the buffer level in the tank. After electrophoresis the slides were drained, placed on a tray and flooded with three changes of neutralization buffer $(0.4 \mathrm{~mol} / \mathrm{l}$ Tris; pH: 7.5; Sigma-Aldrich) for $5 \mathrm{~min}$ each. This removes any remaining alkali and detergents that would interfere with ethidium bromide staining. The slides were then drained and stained with $50 \mu \mathrm{l}$ of $20 \mu \mathrm{g} / \mathrm{ml}$ ethidium bromide (Sigma-Aldrich) and covered with a large coverslip.

\section{Image analysis}

The slides were viewed using a Nikon E600 epifluorescence microscope that was equipped with an excitation filter of 515-560 nm from

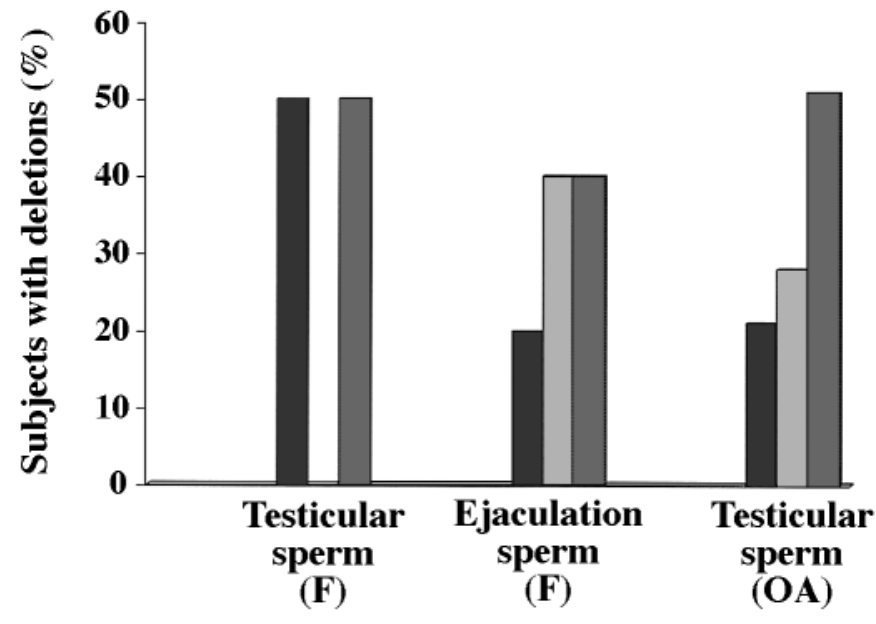

Figure 1. Comparison of the incidence of single, double and multiple deletions in testicular and ejaculated sperm from fertile men (F) and testicular sperm in men with obstructive azoospermia (OA). Single deletion; : Double deletion; I Multiple deletions.

a 100W mercury lamp and a barrier filter of $590 \mathrm{~nm}$. Fifty images were captured and analysed by an image analysis system using the programme Komet 3.1 (Kinetic Imaging Ltd, Liverpool, UK).

\section{Statistical analysis}

MtDNA and nDNA results were analysed using Statistica 5.0 (Statsoft of Europe, Hamburg, Germany). In view of the possible non-Gaussian distribution of data, the non-parametric Wilcoxon matched pairs test was employed to determine the differences between fertile testicular and ejaculated sperm and the Mann-Whitney test for the testicular sperm from both groups. One-way analysis of variance was used to determine the differences between the number of mitochondrial deletions detected and the mean size of the deletion between fertile testicular and ejaculated sperm, and the testicular sperm from men with obstructive azoospermia.

\section{Results}

Testicular sperm from men with obstructive azoospermia and testicular and ejaculated sperm from fertile men were analysed.

\section{Incidence of DNA deletions}

Sixty per cent of fertile subjects had testicular sperm with wild-type (WT) mtDNA, i.e. with no mutations. Only 50\% of the fertile men had ejaculated sperm that contained wild-type DNA. Men with obstructive azoospermia had a slightly lower incidence $(46 \%)$ of wild-type mtDNA profiles in their sperm.

Testicular sperm from half of the fertile subjects contained single deletions while the other half of the group had multiple, i.e. less than two deletions. Ejaculated sperm from the same subjects harboured a lower incidence of single deletions $(20 \%)$ but contained more double deletions (40\%) with the remainder of the men $(40 \%)$ having multiple deletions. In the group with obstructive azoospermia, $21 \%$ of the men had testicular sperm harbouring single deletions, $28 \%$ had sperm with double deletions and (51\%) had sperm with multiple deletions (Figure 1). There was no significant difference between the number of deletions detected within fertile testicular and 


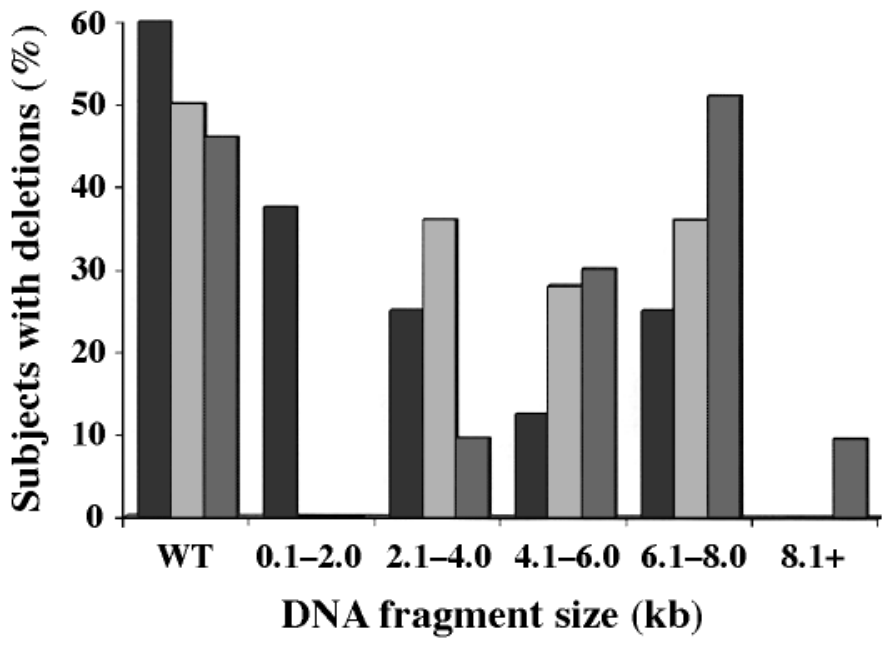

Figure 2. Comparison between mitochondrial DNA deletion size in testicular and ejaculated sperm from fertile men and men with obstructive azoospermia. $\square$ testicular sperm (fertile men); ejaculated sperm (fertile men); testicular sperm from men with obstructive azoospermia. WT $=$ wild type.

ejaculated sperm and the testicular sperm from men with obstructive azoospermia.

\section{Comparison between mtDNA fragment size in testicular and ejaculated sperm from fertile men and men with obstructive azoospermia}

The deletions were divided into five groups according to size: (i) $0.1-2.0 \mathrm{~kb}$, (ii) $2.1-4.0 \mathrm{~kb}$, (iii) $4.1-6.0 \mathrm{~kb}$, (iv) $6.1-8.0 \mathrm{~kb}$ and (v) $8.1+\mathrm{kb}$ (Figure 2). The smallest DNA deletions $(0.1-2.0 \mathrm{~kb})$ were only detected in testicular sperm from fertile men (37.5\%). DNA deletions of 2.1-4.0 kb were detected in all three groups with sperm from obstructive azoospermic men having the lowest percentage (9.5\%), fertile testicular $(25 \%)$ and ejaculated sperm $(36 \%)$ containing the highest incidence of 2.1-4.0 kb deletions. Testicular sperm from men with obstructive azoospermia contained the greatest incidence of larger, i.e. $4.1-6.0 \mathrm{~kb}$ deletions $(30 \%)$. In contrast, testicular sperm from fertile men displayed a low incidence of this deletion $(12.5 \%)$.

Sperm from men with obstructive azoospermia contained most large-scale deletions $(51 \%, 6.1-8.1 \mathrm{~kb}$ and $9.5 \%, 8.1 \mathrm{~kb})$. Neither testicular nor ejaculated sperm from any of the fertile men displayed deletions $>8.1 \mathrm{~kb}$ deletions (Figure 2).

Statistically, there was a difference in the mean fragment size detected between men with obstructive azoospermia and fertile men $(P<0.02)$. The mean deletion size from men with obstructive azoospermia was $3.41 \mathrm{~kb}$, while the mean deletion size from fertile testicular sperm was $1.4 \mathrm{~kb}$.

\section{NDNA fragmentation and correlation between nDNA, mtDNA: deletion and mean $k b$ incidence}

The percentage fragmented testicular sperm DNA from fertile men $(13.5 \%)$ was similar to that from men with obstructive azoospermia (16.6\%). There were no significant differences between testicular and ejaculated sperm from fertile subjects

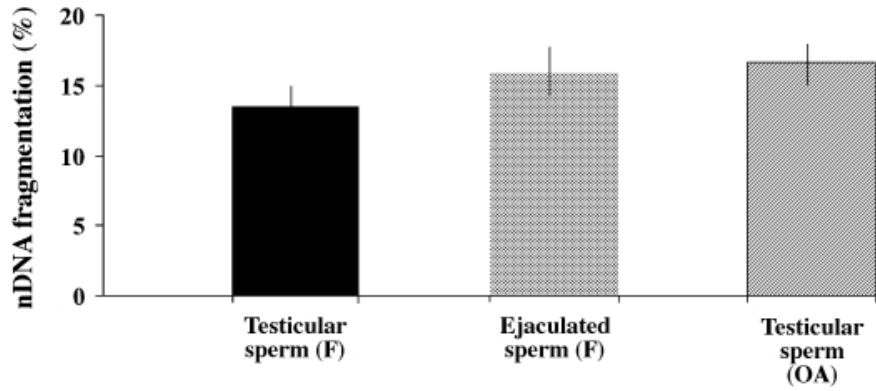

Figure 3. Comparison of nuclear DNA fragmentation in testicular and ejaculated sperm from fertile men and testicular sperm from men with obstructive azoospermia. $\square$ test sperm $(\mathrm{F})=$ testicular sperm (fertile men); i ejaculated sperm $(\mathrm{F})=$ ejaculated sperm (fertile men); $\mathbb{Z}$ test sperm $(\mathrm{OA})=$ testicular sperm from men with obstructive azoospermia.

(Figure 3). There was a strong relationship between nDNA fragmentation and the mean size $(r=0.6, P<0.01)$ of the mitochondrial deletions and number of deletions detected $(r=0.5, P<0.05)$ in men with obstructive azoospermia.

\section{Discussion}

In recent years, semen quality appears to have declined in a number of countries of the Western world including the UK (Carlsen et al., 1992; Swan et al., 2000) although some have contested this claim (Lipshultz, 1996; Joffe, 2000). Defective sperm function accounts for up to $50 \%$ of all the couples attending infertility clinics (Nieschlag et al., 2000) with poor motility being one of the most common sperm problems.

Around the midpiece of sperm is a sheath of mitochondria whose inner membranes facilitate the production of ATP by oxidative phosphorylation (Wallace et al., 1994). If the mitochondria are dysfunctional they may be incapable of providing sufficient ATP for optimal motility (Folgero et al., 1993). In this study we probed the mitochondrial genome in the region located between the D loop and Cox II gene. This region contains the complexes involved in oxidative phosphorylation such as cytochrome $\mathrm{C}$ oxidase, ATPase, NADPH dehydrogenase, cytochrome $\mathrm{b}$ and up to nine tRNAs (Lestienne et al., 1997). Thus, large or multiple deletions may indicate major disruption to the ETC which would alter ATP output and, in turn, future motility.

More than 115 mutations of mtDNA have now been associated with human disease (Kogelnik et al., 1998). These diseases can be subdivided by severity of mutation from deleterious point mutations that predispose individuals to waning conditions such as Alzheimer's and Parkinson's disease (Shoffner et al., 1993) to more harmful mutations that cause disease at an earlier stage, such as Leber's hereditary optic neuropathy (LHON). MtDNA mutations and deletions have now been targeted as the origin of ageing (Shigenaga et al., 1994; Wallace et al., 1994) and also as a cause of male infertility (Cummins et al., 1994; St. John et al., 1997).

The most recent technical advance to detect mtDNA damage in large regions of the genome is by the use of LPCR techniques. This study uses a modified protocol optimized for sperm (St John et al., 1997). One shortcoming of this technique 
is that LPCR amplification may also include elongated spermatids but this is unlikely to include a large proportion of the cells amplified due to the abundance of testicular sperm present in each biopsy sample. In addition, our technique of gently milking the seminiferous tubules, rather than morsellating them, is less likely to dislodge spermatids that are still attached to Sertoli cells. Morphological determination of selected samples also confirmed that they were testicular sperm.

This is the first comparative report of mtDNA fragmentation in testicular sperm from men with obstructive azoospermia and testicular and ejaculated sperm from fertile men. The study provides evidence that testicular sperm from both fertile and infertile men contains multiple mtDNA deletions. This is also true even for the best subpopulation of ejaculated sperm from fertile men. Important to mitochondria are functional membrane potentials, achieved by the pumping of protons across the inner mitochondrial membrane as a result of oxidative phosphorylation (Donnelly et al., 2000).

However, the mitochondrial respiratory system is also the major intracellular source of reactive oxygen species (ROS). These may be generated as by-products during the transfer of electrons in the ETC and complexes to molecular oxygen within the inner mitochondrial membrane. This increase in free radicals may well result in an increase in mtDNA deletions. The most immediate effect of oxidative assault will be observed in the mitochondria since the matrix of the mitochondria is in closest proximity with ROS (Wei, 1998). Sperm mtDNA and nDNA are particularly vulnerable to damage induced by endogenous ROS due to the cell's absence of significant repair mechanisms and high content of membrane polyunsaturated fatty acids (PUFA). This exposure to ROS can progress to plasma membrane damage, through an accumulation of lipid peroxides (Selley et al., 1991). The production of excessive ROS, due to either increased generation or reduced antioxidant protection (Lewis et al., 1995), is now thought to underline many aspects of human male infertility, where sperm are rendered dysfunctional by lipid peroxidation and altered membrane function, together with impaired metabolism and motility (Cummins et al., 1994).

With ongoing concerns about the use of testicular sperm in ICSI treatments (Foresta et al., 1996; te Velde et al., 1998), we wished to confirm our previous study (Steele et al.,1999) that nDNA fragmentation in sperm from men with obstructive azoospermia is comparable with that of testicular sperm from fertile men. Again, the nDNA data presented here would suggest that spermatogenesis continues normally in obstructive azoospermia and that infertility has occurred simply as a result of the reproductive tract obstruction. However, our mtDNA data from the same groups of patients suggest that as well as their infertility being caused by a genital tract blockage, spermatogenesis is defective. Men with obstructive azoospermia had the lowest incidence of wild-type mtDNA profiles in their testicular sperm. They also had the highest incidence of multiple and large-scale mtDNA deletions.

Normally, sperm mtDNA is quantitatively and qualitatively altered during spermatogenesis, possibly to target the mitochondria for destruction during early embryogenesis
(Alcivar et al., 1989). At this stage, abnormal sperm (which can amount to as much as $70 \%$ of total production) is removed by the body's natural mechanism of apoptosis. Recently, it has been suggested that incomplete or 'abortive apoptosis' may explain the high numbers of poor quality sperm observed in the ejaculate of infertile men (Sakkas et al., 1999a). Apoptosis in sperm is mediated by the type I membrane protein Fas. Binding of a Fas ligand (FasL) or an antagonistic anti-Fas antibody to the Fas membrane protein earmarks the cell for apoptotic degradation (Suda et al., 1993). An increase in Fas positivity has been found in ejaculated sperm from infertile men (Sakkas et al., 1999a,b). Since mitochondria are thought to be the primary determinants of cellular life or death our group used a measure of dysfunctional mitochondria as a possible indicator of apoptosis in a previous study (Donnelly et al., 2000). We agree with Sakkas et al. that there is a significant percentage of sperm that may be apoptotic even in the subpopulation isolated by density centrifugation (Sakkas et al.,1999a). Similarly, testicular sperm with a greater incidence of large-scale mtDNA deletions, as occurs in men with obstructive azoospermia, may be a population of sperm that are destined for destruction but have as yet deterred detection. St John et al., have also reviewed the role for mtDNA in sperm survival (St John et al., 2000b). In this article various theories are proposed as to how mtDNA mutations and deletions in sperm arise: the possible relationship between mtDNA and ageing; the implications of ROS; and how mitochondrial membrane potential is affected by mtDNA deletions.

Another factor leading to the compromise of testicular sperm mtDNA in these infertile men, may be the result of blockage that is the primary cause of their azoospermia. MtDNA may be affected by a range of conditions from temperature fluctuations to testicular/epididymal transit times and enzyme additions such as hydrolysing enzymes; hyaluronidase and acrosin from dead and dying sperm acrosomes (Cummins et al., 1994). Here, the damage may be due to oxidative stresses within the testis caused by stasis or from a build-up of localized pressure resulting from the obstruction that culminates in these multiple large-scale deletions (Hess, 1998). It is also possible that this increased pressure delays the release of sperm from the seminiferous tubules leading to premature ageing of the sperm, the effects of which are displayed as accumulated mtDNA deletions. This would concur with reports in other cell types indicating that individual mtDNA deletions accumulate with age in heart (Corral-Debrinski et al., 1991), skeletal muscle (Cortopassi and Arnheim, 1990) and brain (Corral-Debrinski et al., 1994).

It is difficult to explain such a high incidence of abnormality in sperm of healthy, fertile men. Perhaps, in the evolution of the species, the paternal mtDNA of ejaculated sperm are expelled from the embryo at an early stage (Sutovsky et al., 1999), and some of the mechanisms that are present in the oocyte to protect its mtDNA have become obsolete in its male counterpart during sperm differentiation (Reynier et al., 1998). One factor, mitochondrial transcription (Tfam) that is responsible for 
transcription and replication of mtDNA is known to be down-regulated during spermatogenesis. (Larsson et al., 1997). Tfam knockout animals have severe mtDNA depletions and respiratory chain deficiency (Larsson et al., 1998). This decrease of Tfam may also allow an accumulation of mtDNA mutations in sperm of both fertile and infertile men (Reynier et al., 1998).

Further investigations are ongoing to sequence these mitochondrial fragments in order to elucidate the full significance of their deletions.

\section{Acknowledgement}

The authors gratefully acknowledge financial support from the Research and Development Office, Belfast, UK.

\section{References}

Alcivar, A.A., Hake L.E., Millette, C.F.,Trasler, J.M. and Hecht, N.B. (1989) Mitochondrial gene expression in male germ cells of the mouse. Dev. Biol., 135, 263-271.

Biggers, J.D., Whitten, W.K. and Whittingham, D.G. (1971) The culture of mouse embryos in vitro. In Daniel J.C. (ed) Methods in Mammalian Embryology. Freeman Press, San Francisco, USA.

Bohr, V.A. and Dianov, G.L. (1999) Oxidative DNA damage processing in nuclear and mitochondria DNA. Biochimie, 81, 155-160.

Bourgeron, T. (2000) Mitochondrial Function and Male Infertility. In McElreavey, K. (ed) The Genetic Basis of Male Infertility. Springer-Verlag, Heidelberg.

Carlsen, E., Giwercman, A., Keiding, N. and Skakkebaek, N.E. (1992) Evidence for decreasing quality of semen over the past 50 years. Br. Med. $J .$, 305, 609-613.

Corral-Debrinski, M., Horton, T., Lott, M.T., Shoffner, J.M., Beal, M.F. and Wallace, D.C. (1994) Marked changes in mitochondrial DNA deletion levels in Alzheimer brains. Genomics, 23, 471-476.

Corral-Debrinski, M., Stepien, G., Shoffner, J.M., Lott, M.T., Kanter, K. and Wallace, D.C. (1991) Hypoxemia is associated with mitochondrial DNA damage and gene induction-implications for cardiac disease. J.A.M.A., 266, 1812-1816.

Cortopassi, G.A., and Arnheim, N. (1990) Detection of a specific mitochondrial DNA deletion in tissues of older humans. Nucleic Acids Res., 18, 6927-6933.

Croteau, D.L., Stierum, R.H. and Bohr, V.A. (1999) Mitochondrial DNA repair pathways. Mut. Res., 434, 137-148.

Cummins, J.M., Jequier, A.M. and Kan, R. (1994) Molecular biology of human male infertility: links with ageing, mitochondrial genetics, and oxidative stress. Mol. Rep. Dev., 37, 345-362.

Cummins, J.M., Jequier, A.M., Martin, R., Mehmet, D. and Goldblatt, J. (1998) Semen levels of mitochodrial DNA deletions in men attending an infertility clinic do not correlate with pheotype. Int. J. And., 21, 47-52.

Donnelly, E.T., McClure, N. and Lewis, S.E.M. (1999) The effects of ascorbate and $\alpha$-tocopherol supplementation in vitro on DNA integrity and hydrogen peroxide-induced DNA damage in human sperms. Mutagenesis, 14, 505511.

Donnelly, E.T., O'Connell, M., McClure, N. and Lewis, S.E.M. (2000) Differences in nuclear DNA fragmentation and human mitochondrial integrity of semen and prepared human sperms. Hum. Reprod., 15, 15521561.

Folgero, T., Bertheussen, K., Lindal, S., Torbergsen, T. and Oian, P. (1993) Mitochondrial disease and reduced sperm motility. Hum. Reprod., 8, $1863-1868$.

Foresta, C., Rossato, M., Garolla, A. and Ferlin, A. (1996) Male infertility and ICSI: are there limits? Hum. Reprod., 11, 2347-2348.

Hess, R.A. (1998) Effects of environmental toxicants on the efferent ducts, epididymis and fertility. In Jones, R.C, Holland, M.K. and Doberska, C. (eds) The Epididymis: Cellular and Molecular Aspects. The Journals of Reproduction and Fertility Ltd, Cambridge University Press.

Hughes, C.M., Lewis, S.E.M., McKelvey-Martin, V.J. and Thompson, W. (1997) Reproducibility of human sperm DNA measurements using the alkaline single cell gel electrophoresis assay. Mutat. Res., 374, 261-268.
Joffe, M. (2000) Time trends in biological fertility in Britain. Lancet, 355, 1961-1965.

Kao, S.H., Choa, H.T. and Wei, Y.H. (1995) Mitochondrial deoxyribonucleic acid 4977 bp deletion is associated with diminished fertility and motility of human sperm. Bio. Reprod., 52, 729-736.

Kao, S.H., Choa, H.T. and Wei, Y.H. (1998) Multiple deletions of mitochondrial DNA are associated with the decline of motility and fertility of human sperms. Mol. Hum. Reprod., 4, 657-666.

Kogelnik, A.M., Lott, M.T., Brown, M.D. and Wallace, D.C. (1998) MITOMAP: a human mitochondrial genome database-1998 update. Nucleic Acids Res., 26, 112-115.

Kruger, T.F., Menkweld, R., Stander, F.S.H., Lombard, C.J., Van der Merwe, J.P., Van Zyl, J.A. and Smith, K. (1986) Sperm morphological features as a prognostic factor in IVF. Fert. Steril., 46, 1118-1123.

Larsson, N.G., Oldfors, A., Garman, J.D., Barsh, G.S. and Clayton, D.A. (1997) Down-regulation of mitochondrial transcription factor A during spermatogenesis in humans. Hum. Mol. Genet., 6, 185-191.

Larsson, N.G., Wang, J.M., Wilhelmsson, H., Oldfors, A., Rustin, P., Lewandoski, M., Barsh, G.S. and Clayton, D.A. (1998) Mitochondrial transcription factor $\mathrm{A}$ is necessary for mtDNA maintenance and embryogenesis in mice. Nature Genetics, 18, 231-236.

Lestienne, P. (1992) Mitochondrial DNA mutations in human diseases: a review. Biochimie., 74, 123-130.

Lestienne, P., Reynier, P., Chretien, M.F., Penisson-Besnier, I., Malthiery, Y. and Rohmer, V. (1997) Oligoasthenozoospermia associated with multiple mitochondrial DNA rearrangements. Mol. Hum. Reprod., 3, 811-814.

Lewis, S.E.M., Boyle, B.A., McKinney, K.A. and Thompson, W. (1995) Total antioxidant capacity of seminal plasma is different in fertile and infertile men. Fertil. Steril., 64, 868-870.

Lipshultz, L.I. (1996) The debate continues-the continuing debate over the possible decline in semen quality. Fertil. Steril., 65, 909-911.

Nieschlag, E. (2000) Scopes and goals of andrology. In Nieschlag, E. and Behre, H.M. (eds) Andrology: Male Reproductive Health and Dsyfunction. Springer-Verlag, Berlin.

Pesole, G., Gissi, C., de Chirico, A. and Saccone, C. (1999) Nucleotide substitution rate of mammalian mitochondrial genomes. J. Mol. Evol., 48 , 427-343.

Reynier, P., Chretien, M, F., Fredrique, S. Larcher, G., Rohmer, V., Barrientos, A.and Malthiery, Y. (1998) Long PCR analysis of human gamete mtDNA suggests defective mitochondrial maintenance in sperms and supports bottleneck theory for oocytes. Bichem. BioPhy. Res. Comm., 252, 373-377.

Robbins, W.A., Segraves, R., Pinkel, D. and Wyrobeck, A.J. (1993) Detection of aneuploid human sperm by fluorescence in-situ hybridization: evidence for a donor difference in frequency of sperm disomic for chromosomes I and Y. Am. J. Hum. Genet., 52, 799-807.

Sakkas, D., Mariethoz, E., and St John, J.C. (1999a) Abnormal sperm parameters in humans are indicative of an abortive apoptotic mechanism linked to the Fas-mediated pathway. Exp.Cell Res., 251, 350-355.

Sakkas, D., Mariethoz, E., Manicardi, G.C., Bizzaro, D., Bianchi, P.G. and Bianchi, U. (1999b) Origin of DNA damage in ejaculated human sperms. Rev. Reprod., 4, 31-37.

Selley, M.L., Lacey, M.J., Bartlett, M.R., Copeland, C.M. and Ardline, N.G. (1991) Content of significant amounts of a cytotoxic end product of lipid peroxidation in human semen. J. Reprod. Fertil., 92, 291-298.

Shigenaga, M.K., Hagen, T.M. and Ames, B.M. (1994) Oxidative damage and mitochondrial decay in ageing. Proc. Natl Acad. Sci., 91, 10771-10778.

Shoffner, J.M., Brown, M.D., Torroni, A., Lott, M.T., Cabell, M.R., Mirra, S.S., Beal, M.F., Yang, C., Gearing, M., Salvo, R. et al. (1993) MtDNA variants observed in Alzheimer's disease and Parkinson's disease patients. Genomics, 17, 171-184.

St John, J. C., Cooke, I.D. and Barratt, C.L.R. (1997) The use of Long PCR to detect multiple deletions in the mtDNA of human testicular tissue from azoospermic and severe oligoospermic patients. In Barratt, C.L.R., De Jonge, C. and Mortimer, D. (eds.) Genetics of Human Male Fertility. EDK.

St John, J.C., Sakkas, D and Barratt, C.L.R. (2000b) A role for mtDNA and sperm survival. J. Androl., 21, 189-199.

St John, J.C., Sakkas, D., Dimitriadi, K., Barnes, A., Maclin, V., Ramey, J., Barratt, C. L. R. and De Jonge, C.J. (2000) Failure of elimination of paternal mitochondrial DNA in abnormal embryos. Lancet, 353, 200.

Steele, E.K., Kelly, J.D., Lewis, S.E.M., McNally, J.A., Sloan, J.M. and McClure, N. (2000) Testicular sperm extraction by Trucut needle and milking of seminiferous tubules: a technique with high yield and patient acceptability. Fertil. Steril., 74, 380-383. 
Steele, E.K., McClure, N., Maxwell, R.J. and Lewis, S.E.M. (1999) A comparison of DNA damage in testicular and proximal epididymal sperms in obstructive azoospermia. Mol. Hum. Reprod., 5, 831-835.

Suda, T., Takahashi, T., Golstein, P. and Nagata, S. (1993) Molecular cloning and expression of the Fas ligand, a novel member of the tumor necrosis factor family. Cell, 75, 69-78.

Sutovsky, P., Moreno, R.D., Ramalho-Santos, J., Dominko, T., Simerly, C. and Schatten, G. (1999) Ubiquitin tag for sperm mitochondria. Nature, 402, 371-372.

Swan, S.H., Elkin, E.P. and Fenster, F. (2000) The question of declining sperm density revisited: An analysis of 101 studies published 1934-1996. Env. Health. Per., 108, 961-966.

te Velde, E.R., van Barr, A.L. and van Kooij, R.J. (1998) Concerns about assisted reproduction. Lancet, 351, 1524-1525.
Wallace, D.C. (1993) Mitochondrial diseases: genotype versus phenotype. Trends Genet., 9, 128-133.

Wallace, D.C., Lott, M.R., Shoffner, J.M., and Ballinger, S. (1994) MtDNA mutations in epilepsy and neurological disease, Epilepsia, 35 (Suppl.1), 43-50.

Wei, Y.H. (1998) Oxidative stress and mitochondrial DNA mutations in human ageing. P.S.E.B.M., 214, 53-63.

World Health Organization (1999) WHO laboratory Manual for the Examination of Human Semen and Sperm-Cervical Mucus Interactions, 4th edn. University of Cambridge Press Syndicate, Cambridge, UK.

Submitted on August 21, 2001; resubmitted on December 7, 2001; accepted on February 25, 2002 